\title{
Deletion of Glucose Transporter GLUT8 in Mice Increases Locomotor Activity
}

\author{
S. Schmidt • V. Gawlik $\cdot$ S. M. Hölter $\cdot$ R. Augustin $\cdot$ A. Scheepers $\cdot$ \\ M. Behrens · W. Wurst · V. Gailus-Durner · H. Fuchs · M. Hrabé de Angelis • \\ R. Kluge $\cdot$ H.-G. Joost $\cdot$ A. Schürmann
}

Received: 22 November 2007 / Accepted: 14 April 2008/Published online: 7 May 2008

(C) The Author(s) 2008

\begin{abstract}
Transport of glucose into neuronal cells is predominantly mediated by the glucose transporters GLUT1 and GLUT3. In addition, GLUT8 is expressed in some regions of the brain. By in situ hybridization we detected GLUT8-mRNA in hippocampus, thalamus, and cortex. However, its cellular and physiological function is still unknown. Thus, GLUT8 knockout $\left(\operatorname{Slc} 2 a 8^{-/-}\right)$mice were used for a screening approach in the modified hole board (mHB) behavioral test to analyze the role of GLUT8 in the central nervous system. Slc $2 a 8^{-1-}$ mice showed increased mean velocity, total distance traveled and performed more turns in the mHB test. This hyperactivity of Slc $2 a 8^{-1-}$ mice was confirmed by monitoring locomotor activity in the home cage and voluntary activity in a running wheel. In addition, Slc $2 a 8^{-1-}$ mice showed increased arousal as indicated by elevated defecation, reduced latency to the first defecation and a tendency to altered grooming. Furthermore, the mHB test gave evidence that Slc $2 a 8^{-I-}$ mice exhibit a reduced risk assessment because
\end{abstract}

Edited by Stephen Maxson.

S. Schmidt · V. Gawlik · R. Augustin · A. Scheepers ·

R. Kluge · H.-G.Joost · A. Schürmann ( $\square)$

Department of Pharmacology, German Institute of Human

Nutrition Potsdam-Rehbruecke, Arthur-Scheunert-Allee

114-116, 14558 Nuthetal, Germany

e-mail: schuermann@dife.de

S. M. Hölter · W. Wurst · V. Gailus-Durner · H. Fuchs · M. H. de Angelis

German Mouse Clinic, GSF National Research Center

for Environment and Health, Neuherberg, Germany

M. Behrens

Department of Molecular Genetics, German Institute of Human

Nutrition Potsdam-Rehbruecke, 14558 Nuthetal, Germany they performed less rearings in an unprotected area and showed significantly reduced latency to stretched body posture. Our data suggest that behavioral alterations of Slc $2 a 8^{-1-}$ mice are due to dysfunctions in neuronal processes presumably as a consequence of defects in the glucose metabolism.

Keywords Glucose transport - Modified hole board test . Behavioral screen $\cdot$ Knockout mice

\section{Introduction}

Glucose is the major source of energy for the mammalian brain. Reduced glucose levels lead to decreased memory processing, whereas increased glucose levels can be used as a positive mediator of memory (Convit et al. 2003). In addition, a number of studies implicated that a reduced glucose metabolism in the entorhinal cortex (Killiany et al. 2000), hippocampus (Jack et al. 1999; Ouchi et al. 1998), temporal neocortex (Convit et al. 2000) and posterior cingulate gyrus (Johnson et al. 1998) is associated with Alzheimer's disease. In addition, Alzheimer's disease is linked to decreased expression of glucose transporters of the GLUT family, such as the neuronal glucose transporter GLUT3 in hippocampal dentate gyrus (Harr et al. 1995) and cerebral cortex (Simpson et al. 1994).

Glucose transporters of the GLUT family catalyze the transport of hexoses across membranes of mammalian cells by facilitative diffusion. The family consists of $14 \mathrm{mem}-$ bers that differ in their tissue distribution, substrate specificity, and kinetics of transport. According to sequence similarities it can be divided into three classes (Joost and Thorens 2001). GLUT8 belongs to the class III transporters which are described to be located in 
intracellular compartments. So far, a stimulus leading to plasma membrane translocation of GLUT8 has not been found (Lisinski et al. 2001; Widmer et al. 2005). GLUT8 transports glucose with high affinity $\left(K_{\mathrm{m}}=2 \mathrm{mM}\right)$ (Ibberson et al. 2000) and is mainly expressed in testis and brain but also in muscle, adipose tissue, liver, and most other tissues to a lesser extent. We have recently shown that deletion of GLUT8 results in decreased sperm motility as a consequence of reduced ATP levels and a reduced mitochondrial membrane potential of sperm cells indicating that GLUT8 is involved in energy metabolism of sperm (Gawlik et al. 2008).

In the central nervous system of rats, first GLUT8 mRNA was detected in hippocampal pyramidal neurons and granule neurons of the dentate gyrus as well as in nonprincipal neurons (Reagan et al. 2001). Later, GLUT8 protein was found in hippocampal and dentate gyrus neurons as well as in amygdala and primary olfactory cortex, cerebellum and hypothalamus of rats by immunohistochemistry (Ibberson et al. 2002). Several of these regions are implicated in learning and memory (Bliss and Collingridge 1993; Nakazawa et al. 2002), fear and anxiety (Deacon et al. 2002), hyperactivity (Bannerman et al. 2001) and exploration (Honey et al. 2007).

In order to evaluate the role of GLUT8 in the mouse brain specifically for locomotor activity and anxiety-related behavior we first analyzed its distribution by in situ hybridization and obtained initial behavioral phenotyping from naïve control mice and knockout mice lacking the GLUT8 encoding gene (Slc2a8) with the modified hole board test. With this approach we aimed to detect differences in the attitude of wild-type and Slc $2 a 8^{-1-}$ mice which were then verified by an additional analysis. While our study was in progress, it was described that $S l c 2 a 8^{-/-}$ mice exhibited an increased proliferation of hippocampal cells (Membrez et al. 2006). However, no differences in memory acquisition and retention were observed (Membrez et al. 2006). Here we describe that deletion of Slc2a8 in mice induces hyperactivity and give evidence of increased emotional reactivity to a novel environment.

\section{Materials and methods}

Mice

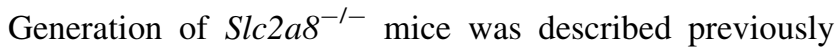
(Gawlik et al. 2008). Briefly, the Cre loxP system was used for generation of R1 ES cells (129S3/SvImJ background) lacking exons 5-7 of Slc2a8 in order to generate Slc2a8 ${ }^{-1-}$ mice. As described (Gawlik et al. 2008), a targeting vector in which exons 5 and 7 of Slc2a8 were flanked with two loxP sites, and a PGKneo/HSVtk cassette (Neo/tk) with a third loxP site which was introduced downstream of the flanked exon seven was cloned and transfected into ES cells. Homologously recombined ES cell clones carrying the targeted allele were transfected with pCre in order to express the Cre recombinase transiently. ES cells with a recombination between the 1 and the 3 . loxP site carrying the deleted allele were used for a morula aggregation. Blastocysts were then transferred into a pseudopregnant (day 2.5) female mouse and male chimeric mice were mated with C57BL/6 females. Mice carrying the transgene were backcrossed with C57BL/6 mice for 3 times and subsequently intercrossed. Genotyping of mice was performed by PCR (forward primer: $5^{\prime}$-CATCTTCTGTG CAGTCCATC- ${ }^{\prime}$, reverse primer: 5'-GGTACCAAAGGC ACTCATACTG-3') (Fig. 1b). In order to minimize phenotypical differences as a result of heterogenous genetic background of C57BL/6 and 129S3/SvlmJ we analyzed Slc $2 a 8^{+/+}$and Slc2a8 ${ }^{-1-}$ littermates of 5-7 litters at the same time for each set of experiments. Mice had free access to water and standard mice chow and were group housed in air conditioned rooms (temperature $20 \pm 2^{\circ} \mathrm{C}$, relative moisture 50-60\%) under a $12 \mathrm{~h} / 12 \mathrm{~h}$ light/dark cycle. They were kept in accordance with the NIH guidelines for the care and use of laboratory animals, and all experiments were approved by the ethics committee of the Ministry of Agriculture, Nutrition, and Forestry (State of Brandenburg, Germany).

In situ hybridization

About $20 \mu \mathrm{m}$ sections of frozen mouse brains were cut and thaw mounted onto positively charged glass slides. Before hybridization, the sections were fixated with $4 \%$ paraformaldehyde in PBS, permeabilized with $0.2 \mathrm{M}$ hydrochloric acid for $10 \mathrm{~min}$ and $1 \%$ Triton X-100 in PBS for $2 \mathrm{~min}$, and acetylated by treatment with $0.1 \mathrm{M}$ triethanolamine $0.25 \%$ acetic anhydride, $\mathrm{pH}$ 8.0. Prehybridization was performed at $50^{\circ} \mathrm{C}$ for $5 \mathrm{~h}$, followed by hybridization overnight at $50^{\circ} \mathrm{C}$. Riboprobes were generated as follows: a PCR-fragment of the Slc $2 a 8$ gene (forward primer: GTC CTA GAG TGG CGC TGG; reverse primer: CTG TCC ATG ATG AGG GCC) was generated with a Pfu polymerase and cloned into the TOPO vector (Clontech Inc., Carlsbad, USA). Plasmids were linearized and riboprobes generated with the T7 polymerase and the DIG RNA labeling kit (Roche Diagnostics, Indianapolis, USA). Probes were used for hybridization at a final concentration of $500 \mathrm{ng} / \mathrm{ml}$. After hybridization, the slides were washed several times at low stringency, followed by RNAase treatment and high-stringency washes with $0.4 \times \mathrm{SSC}$ buffer at $50^{\circ} \mathrm{C}$. Hybridized riboprobes were detected with an anti-digoxigenin antibody and colorimetry. 


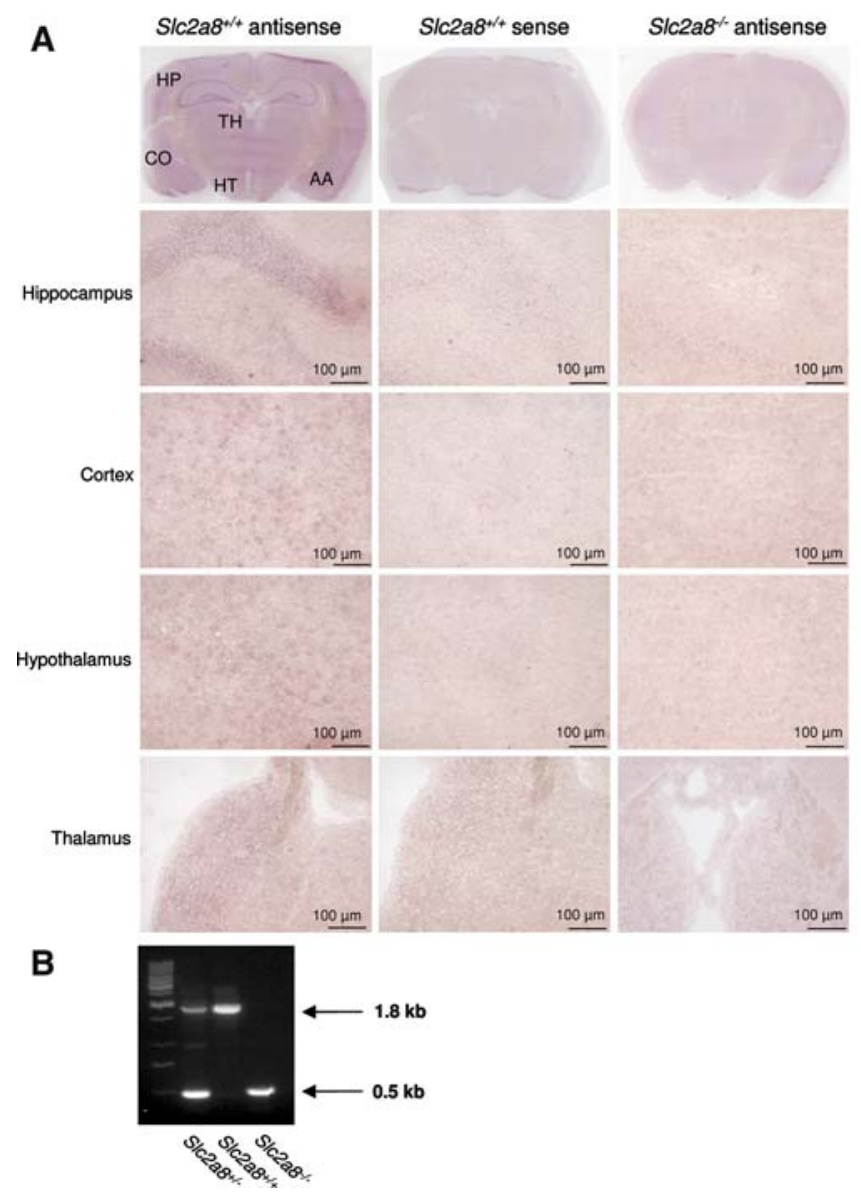

Fig. 1 Analyses of GLUT8 expression in mouse brains by in situ hybridization. (a) $20 \mu \mathrm{m}$ cross-sections of mouse brains were hybridized with GLUT8-specific digoxigenin-labeled riboprobes and stained by standard colorimetry as described in Material and methods. Signals were obtained with the antisense probes (left panel), whereas sections of Slc $2 a 8^{-/-}$brains did not show signals (right panel). As an additional control, brain sections from wild-type mice were incubated with probes corresponding to the sense strands of GLUT8 (middle panels). AA, amygdala; CO, cortex; HP, hippocampus; TH, thalamus; HT, hypothalamus. (b) Genotyping of mice was performed by PCR as

RNA preparation and first strand cDNA synthesis

RNA was extracted from different brain areas and cDNA synthesis was performed as previously described (Buchmann et al. 2007). Quality of cDNA was controlled performing a PCR with murine GAPDH primers (forward: 5'-ACC ACA GTC CAT GCC ATC AC-3'; reverse, 5'-TCC CAC CAC CCT GTT GCT GTA-3').

\section{Quantitative real-time PCR}

qRT-PCR analysis was performed with the Applied Biosystems 7300 RT-PCR System as described previously (Buchmann et al. 2007). The TaqMan gene expression assay (Mm00444635_g1) was used to detect the GLUT8mRNA expression. The assay amplifies the region between

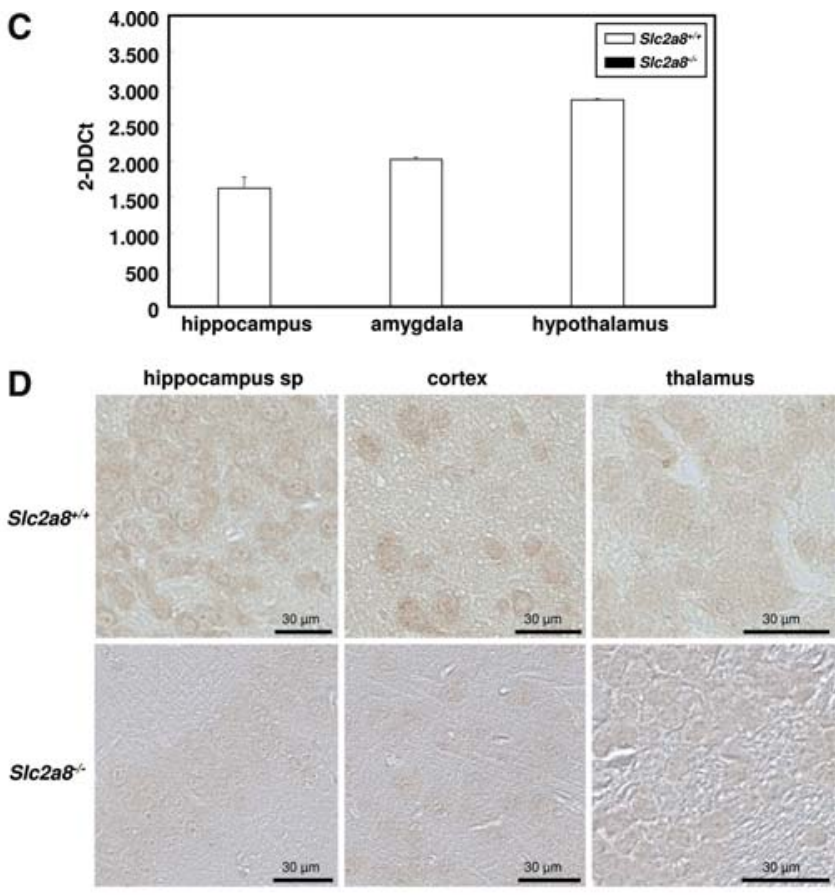

described in Material and methods. (c) Slc2a8 mRNA levels of Slc $2 a 8^{+/+}$and Slc $2 a 8^{-/-}$littermates in hippocampus, amygdala, and hypothalamus were assayed by quantitative real time-PCR (qRTPCR) as described in Material and methods. (d) Immunohistochemical detection of GLUT8 in the hippocampus, cortex, and thalamus. Sections of the brain from Slc $2 a 8^{+/+}$and Slc $2 a 8^{-/-}$mice were fixed with paraformaldehyde and incubated with the anti-GLUT8 antiserum. The immunostaining was performed with peroxidase-conjugated secondary antibody as described in Material and methods

exons 5 and 6, which is deleted in Slc2a $8^{-1-}$ mice. Data were normalized referring to Livak and Schmittgen (2001), whereas a $\beta$-actin expression assay (Mm00607939_si; Applied Biosystems) was used as endogenous control.

\section{Immunohistochemical detection of GLUT8}

Paraffin sections of brains from Slc $2 a 8^{+/+}$and Slc $2 a 8^{-1-}$ males were stained for GLUT8 as described previously (Gawlik et al. 2008). Briefly, sections were incubated with an affinity purified polyclonal anti-GLUT8 antibody in a concentration of $1 \mu \mathrm{g} / \mathrm{ml}$ and specific antibody binding was visualized by biotin-conjugated donkey anti-rabbit IgG (1:800; Dianova, Hamburg, Germany), for $30 \mathrm{~min}$ at $37^{\circ} \mathrm{C}$, followed by incubation with a streptavidin-biotin-horseradish peroxidase complex (StreptAB-complex/POD) for 
$30 \mathrm{~min}$, and diaminobenzidine as substrate according to the manufacturer's specifications. Microscopic investigation and photo documentation were done with the combined light and fluorescence microscope ECLIPSE E-100 (Nikon, Düsseldorf, Germany) in combination with the video camera CCD-1300CB (Vosskühler, Osnabrück, Germany) and the Analysis System LUCIA G (Nikon, Düsseldorf, Germany).

Modified hole board (mHB) test

The mHB test was performed with 8-weeks old naïve mice which were kept in the test room of the German mouse clinic for 1 week under standard laboratory conditions before the experiment. The $\mathrm{mHB}$ comprises the characteristics of a hole board to investigate exploration in rodents (File and Wardill 1975; Lister 1990), and an open field, a test that is frequently used to evaluate locomotor activity (Kelley 1993). The mHB test was conducted as previously reported (Kallnik et al. 2007), in a modified version of the procedure developed by Ohl and coworkers (1998; 1999; 2001). The board consisted of opaque gray PVC $(60 \times 20 \times 2 \mathrm{~cm})$ with 23 holes $(1.5 \times 0.5 \mathrm{~cm})$ staggered in three lines. All holes on the board were covered by motile lids. The board was placed in the middle of a PVC box $(100 \times 50 \times 50 \mathrm{~cm})$, thus representing the central area of an open field. The outer area was divided into 12 similarly sized quadrants by white lines. Both box and board were made of dark grey PVC. All lids were closed before the start of a trial. For each trial, a familiar object (metal cube) and an unfamiliar object (a blue plastic tube lid, similar in size to the metal cube) were placed into the test arena with a distance of $2 \mathrm{~cm}$ between them. A copy of the familiar object had been placed in the animals' home cages for 3 days and removed 1 day before testing. A hole or object was counted as explored if the nose of the animal poked over it. The illumination levels were set at approximately 150 lux in the corners and 200 lux in the middle of the test arena.

For testing, each animal was placed individually into the test arena and allowed to explore it freely for $5 \mathrm{~min}$. The animals were always placed into the test arena in the same corner, facing the board diagonally. The two objects were placed in the corner quadrant diametrical to the starting point. During the 5 min trial, the animal's behavior was recorded by a trained observer with a hand-held computer in a blinded study. After each trial, the test arena was cleaned carefully with a disinfectant.

The mHB test was performed in the morning between 9.00 a.m. and 12.00 noon, the behavioral parameters, such as line crossings, rearings, board entries, hole exploration, object exploration, grooming, defecation, and immobility were scored. Data were analyzed by using the Observer 4.1
Software (Noldus, Wageningen). Additionally, a camera was mounted $1.20 \mathrm{~m}$ above the center of the test arena, and the animal's track was videotaped and its locomotor path analyzed with a video-tracking system (Ethovision 2.3, Noldus). The parameters total distance traveled, mean and maximum velocity, turns, turn angles, angular velocity, meander, maximum duration on board and distance to wall were calculated from the videotrack data.

Locomotor and running wheel activity

After weaning, before detection of locomotor activity mice were group housed and had free access to water and standard mice chow as described above. Locomotor activity was monitored with an infrared detector (TSE InfraMot-Activity System, TSE, Bad Homburg, Germany) with single housed mice as described previously (Jurgens et al. 2006). The voluntary activity was recorded with an automated running wheel system (TSE) as described previously (Jurgens et al. 2006). Slc $2 a 8^{+/+}$and Slc $2 a 8^{-1-}$ mice at the age of 6 weeks were adapted for 2 days to the type III Macrolon cages or to the running wheels, data were then collected for $24 \mathrm{~h}$. The animals had free access to the running wheels as well as to food and water. The system recorded each quarter-revolution of the wheel, and data were expressed as total number of revolutions per $10 \mathrm{~min}$.

\section{Statistics}

Data were statistically analyzed by unpaired $t$-tests using SPSS software (SPSS Inc, Chicago, USA). The chosen level of significance was $P<0.05$.

\section{Results}

GLUT8 mRNA is present in different brain areas.

In order to analyze the expression of GLUT8 within the brain of mice, we performed in situ hybridization of frozen brain sections from Slc $2 a 8^{+/+}$and $S l c 2 a 8^{-/-}$mice with GLUT8-specific riboprobes. As shown in Fig. 1, mRNA expression of GLUT8 was detected within the hippocampus, cortex, thalamus, and hypothalamus of Slc $2 a 8^{+/+}$ mice while no signals were detected in brain sections of Slc $2 a 8^{-1-}$ mice. The specificity of the signals obtained with the antisense probe was also demonstrated with the sense probe incubated on adjacent sections which did not detect GLUT8 mRNA (Fig. 1). A complete deletion of GLUT8 in the brain of Slc $2 a 8^{-/-}$mice was already described previously (Gawlik et al. 2008). In order to evaluate the deletion of GLUT8 in the different areas of the brain qRT-PCR was performed on the mRNA of 
Fig. 2 Hyperactivity of Slc $2 a 8^{-1-}$ mice detected in the modified hole board $(\mathrm{mHB})$ test. Slc $2 a 8^{+/+}$and Slc $2 a 8^{-/-}$mice at the age of 8 weeks were monitored in the mHB test for 5 min. (a) Mean velocity, (b) total distance traveled, (c) line crossings, and (d) turns of Slc $2 a 8^{-/-}$males $(n=15)$ were compared to Slc $2 a 8^{+/+}$males $(n=15)$. Data are presented as mean + S.E.M. $* P<0.05$; $* * P<0.01 ; * * * P<0.001$
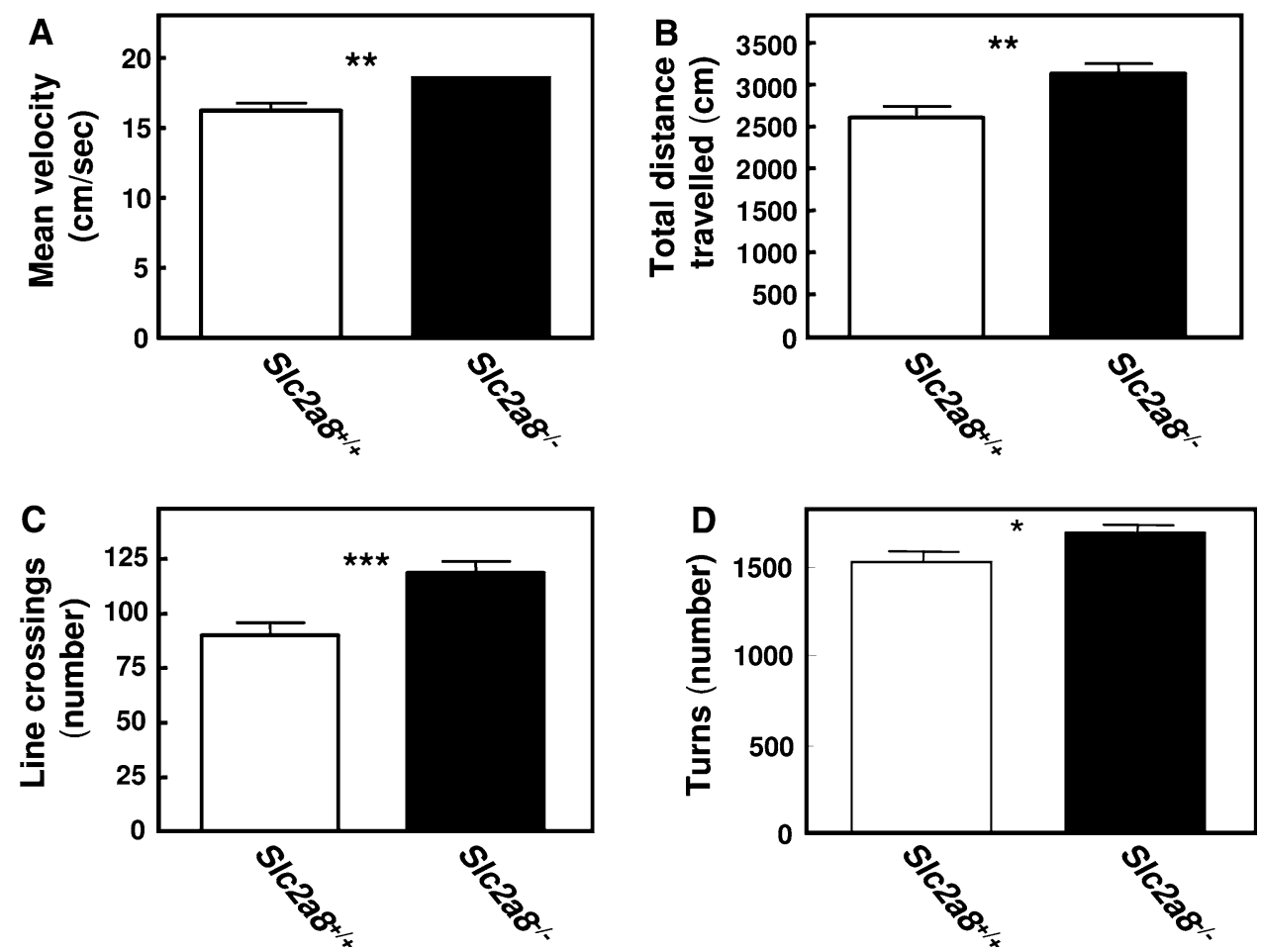

hippocampus, hypothalamus, and amygdala of $\operatorname{Slc} 2 a 8^{+/+}$, and Slc2a $8^{-1-}$ mice. No full-length mRNA of Slc2a8 was detected in samples of Slc $2 a 8^{-1-}$ mice (Fig. 1c) confirming results obtained from total brain and other tissues of Slc $2 a 8^{-1-}$ mice (Gawlik et al. 2008). In addition, immunohistochemical analysis of brain sections performed with an affinity purified anti-GLUT8 antibody demonstrate that within the hippocampus GLUT8 is located in intracellular compartments of wild-type mice but absent in the corresponding region of $S l c 2 a 8^{-/-}$mice (Fig. 1d).

\section{Hyperactivity in $S l c 2 a 8^{-/-}$mice}

To analyze the unconditioned behavior of Slc $2 a 8^{-1-}$ mice in comparison to their wild-type littermates the mHB test was used. This test is described to determine a variety of behavioral dimensions in only one test. In the mHB test, 8 weeks old Slc $2 a 8^{-1-}$ males were hyperactive in comparison to their wild-type littermates. Slc $2 a 8^{-1-}$ mice showed significantly $(P<0.01)$ increased mean velocity (Fig. 2a), and total distance traveled ( $P<0.01$; Fig. 2b). In addition, Slc $2 a 8^{-/-}$mice displayed increased number of line crossings $(P<0.001$; Fig. $2 \mathrm{c})$ and performed more turns $(P<0.05$; Table 1$)$. To further address the role of neuronal GLUT8 for activity we monitored the locomotor activity in the home cage after a $48 \mathrm{~h}$ adaptation period of another set of animals. As shown in Fig. 3a, 6 weeks old Slc $2 a 8^{-1-}$ males exhibited significantly $(P<0.01)$ increased locomotor activity during the dark phase and in the total $24 \mathrm{~h}$ period $(P<0.01)$. Likewise, voluntary activity in the running wheel was significantly higher in $S l c 2 a 8^{-/-}$mice than in Slc2a $8^{+/+}$controls both in the dark phase $(P<0.001)$ and in the total $24 \mathrm{~h}$ period $(P<0.001$ Fig. 3b). During the light phase, neither general locomotor or running wheel activity was different between the genotypes.

Exploratory motivation of Slc $2 a 8^{-1-}$ mice

To address the question if the hyperactivity of Slc $2 a 8^{-1-}$ animals is associated with altered exploratory motivation we analyzed the exploration of holes (Fig. 4a) as well as unfamiliar (blue plastic tube lid Fig. 4b) and familiar objects (metal cube Fig. 4b). However, holes and objects were explored in the same frequency by $S l c 2 a 8^{+/+}$and Slc $2 a 8^{-l-}$ males. Accordingly, the latencies to hole and object exploration were not altered in $S l c 2 a 8^{-1-}$ males (Table 1).

Evidence for increased arousal and reduced risk

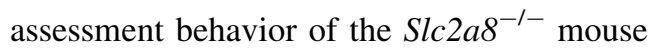

In addition to the assessment of the described parameter on locomotor activity, the mHB test allows the investigation of additional behavioral parameters. As described by Ohl et al. (2003) the latency to the first board entry and the numbers of entries on the board reflect the anxiety of the animals. As shown in Fig. 5 both, the entries (Fig. 5a) and the time on board (Fig. 5b) show only the tendency to be reduced without reaching significant values. 
Table 1 Comparison of additional behavioral parameters of Slc $2 a 8^{-1-}$ mice and wild-type littermates displayed in the mHB. $(n=15)$

\begin{tabular}{|c|c|c|c|}
\hline \multirow[t]{2}{*}{ Parameter } & \multicolumn{2}{|l|}{ Male } & \multirow[t]{2}{*}{ Significance } \\
\hline & Slc $2 a 8^{+/+}$ & Slc $2 a 8^{-1-}$ & \\
\hline Turns (frequency) & $1519.13 \pm 58.1$ & $1687 \pm 48.76$ & $P<0.05$ \\
\hline Hole exploration (frequency) & $58.47 \pm 5.54$ & $53.4 \pm 3.87$ & n.s. \\
\hline Latency to hole exploration (s) & $30.03 \pm 8.37$ & $24.57 \pm 4.84$ & n.s. \\
\hline Unfamiliar object exploration (frequency) & $6.27 \pm 0.65$ & $7.47 \pm 0.62$ & n.s. \\
\hline Latency to unfamiliar object exploration (s) & $54.25 \pm 6.67$ & $45.04 \pm 7.59$ & n.s. \\
\hline Familiar object exploration (frequency) & $6.27 \pm 0.5$ & $7.2 \pm 0.99$ & n.s. \\
\hline Latency to familiar object exploration (s) & $53.73 \pm 12.4$ & $46.69 \pm 5.79$ & n.s. \\
\hline Risk assessment (frequency) & $0 \pm 0.0$ & $0.4 \pm 0.21$ & n.s. \\
\hline Grooming (latency) & $163.53 \pm 21.82$ & $138.49 \pm 20.76$ & n.s. \\
\hline Grooming (total duration \%) & $1.7 \pm 0.32$ & $2.17 \pm 0.41$ & n.s. \\
\hline
\end{tabular}

The latency to the first grooming and the number of feces was described as indicators for arousal (Ohl et al. 2003). The grooming latency was slightly but not significantly reduced, and the grooming number (Fig. 5c), and grooming duration were slightly enhanced in mice lacking
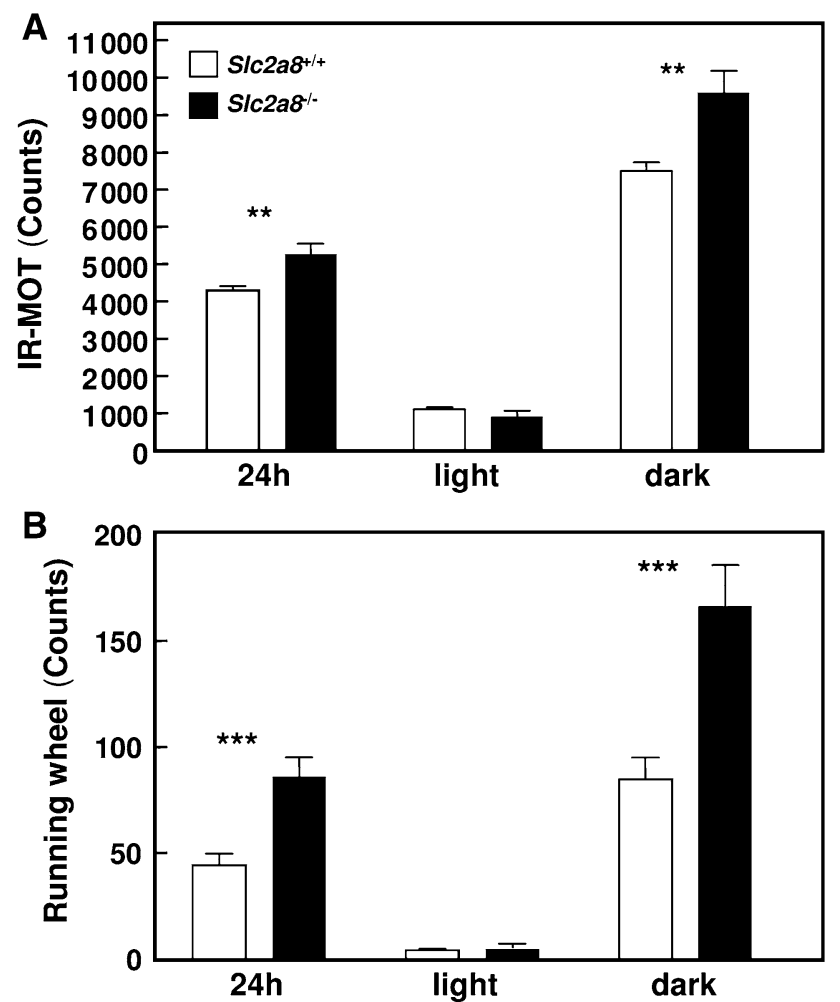

Fig. 3 Hyperactivity of Slc $2 a 8^{-1-}$ mice detected in the home cage. (a) Monitoring locomotor activity and (b) voluntary physical activity of 6 weeks old Slc $2 a 8^{+/+}$and Slc $2 a 8^{-/-}$males. Cages were equipped with an infrared detector and voluntary running wheels, and activities of mice were monitored after an adaptation period of 2 days. Means of activities during the indicated time spans were calculated for each individual animal for the dark and light phase over a period of $24 \mathrm{~h}$. Data are presented as mean + S.E.M. of $9 S l c 2 a 8^{+/+}$and 12 Slc $2 a 8^{-1-}$ mice. $* * P<0.01 ; * * * P<0.001$
GLUT8 (Table 1). Furthermore, the latency to defection was significantly $(P<0.01)$ reduced (control: $244.26 \pm 29.87$ vs. Slc $2 a 8^{-1-}$ mice: $\left.113.13 \pm 30.18 \mathrm{~s}\right)$ and Slc $2 a 8^{-l-}$ mice produce more feces during the testing $(P<0.001$; Fig. 5d) indicating that arousal of the knockout mice appears to be slightly increased.

In addition, Slc $2 a 8^{-1-}$ mice displayed decreased rearings on board $(P<0.001$, Fig. 6a) but increased rearings on box $\left(P<0.05\right.$, Fig. 6b). Consistent to this, Slc2a8 ${ }^{-1-}$ mice started rearing on box earlier than control mice, indicated by decreased latency to rearing on box (Table 1). The stretched attends are like reduced rearings on board monitored in the mHB test as an indicator for risk assessment behavior (Ohl et al. 2003). As shown in Fig. 6c we detected a significantly reduced latency to stretched body posture in Slc2a ${ }^{-1-}$ mice in comparison to wild-type littermates. Out of 15 Slc $2 a 8^{-/-}$males four animals displayed risk assessment behavior indicated by a stretched body posture, whereas none of the control males showed this behavior during the entire $300 \mathrm{~s}$ of the mHB test.

\section{Discussion}

This study demonstrates that GLUT8 is mainly expressed in the hippocampus and that disruption of GLUT8 results in hyperactivity, both in a novel environment and during the active (dark) phase in the home cage. Our findings suggest that GLUT8 is required for glucose metabolism in the hippocampus in order to enable appropriate neuronal processes.

By in situ hybridization, GLUT8 was shown to be strongly expressed in hippocampus, cortex and to a lesser content in the thalamus and hypothalamus (Fig. 1). Thus, we confirmed the previous results obtained in rat brain. Within the rat hippocampus GLUT8 was localized in the granule cells of the dentate gyrus and in the pyramidal cells of the CA1-CA4. In addition, GLUT8 was also detected in 
Fig. 4 Exploration activity of Slc $2 a 8^{-1-}$ mice. Slc $2 a 8^{+/+}$and Slc $2 a 8^{-1-}$ mice at the age of 8 weeks were monitored in the $\mathrm{mHB}$ test for $5 \mathrm{~min}$ with the focus on exploration of holes (a) and objects (B)

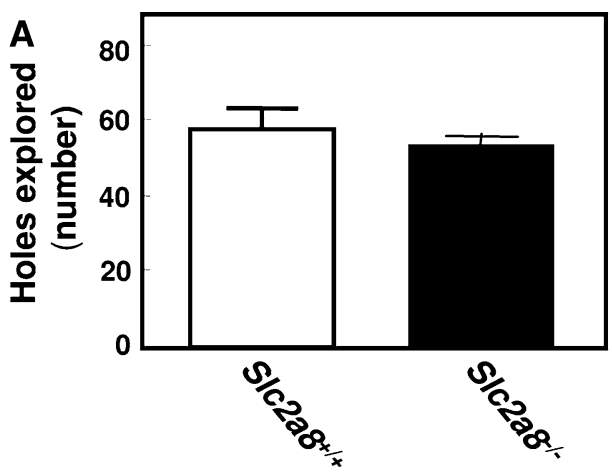

B
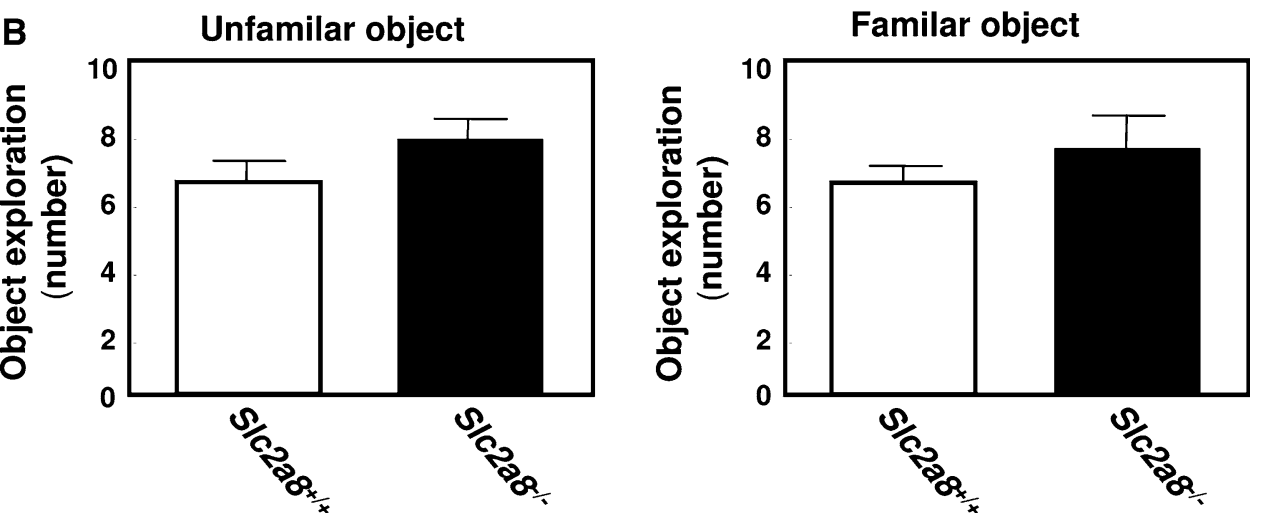

Fig. 5 Behavior of Slc $2 a 8^{-1-}$ mice on the board. Slc $2 a 8^{+/+}$ and $S l c 2 a 8^{-1-}$ mice at the age of 8 weeks were monitored in the $\mathrm{mHB}$ for $5 \mathrm{~min}$. (a) board entries, (b) percentage of time spent on the board, (c) grooming, and (d) defecation of Slc $2 a 8^{-l-}$ males $(n=15)$ were compared to Slc $2 a 8^{+/+}$males $(n=15)$. Data are presented as mean + S.E.M. $* * P<0.01$
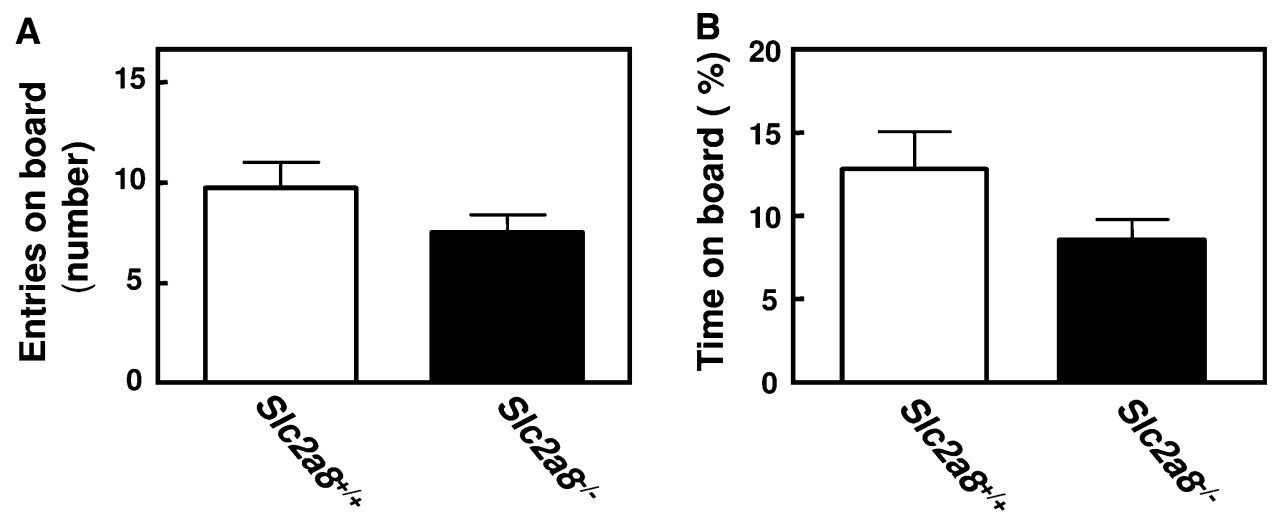

C
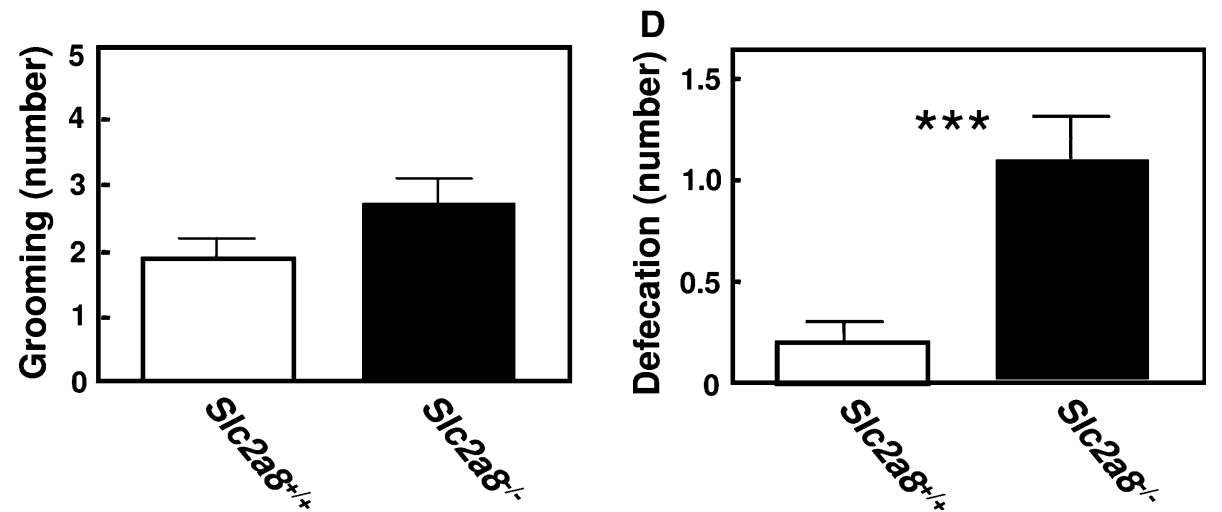

the amygdala (Ibberson et al. 2002; Reagan et al. 2001; Sankar et al. 2002). Since the hippocampus, cortex, and amygdala are known to play an important role in learning and memory (Bliss and Collingridge 1993; Nakazawa et al. 2002), exploration (Honey et al. 2007), fear and anxiety (Bannerman et al. 2003; Bardgett et al. 2003; Deacon et al. 
Fig. 6 Exploratory strategy of Slc $2 a 8^{-/-}$mice. Slc $2 a 8^{+/+}$and Slc $2 a 8^{-1-}$ mice at the age of 8 weeks were monitored in the $\mathrm{mHB}$ for $5 \mathrm{~min}$. (a) rearings on board, (b) rearings on box and (c) latency to stretched body posture of 8 weeks old Slc $2 a 8^{+1}$ ${ }^{+}$males $(n=15)$ were compared to Slc $2 a 8^{-1-}$ males $(n=15)$. Data are presented as mean + S.E.M. $* P<0.05$; $* * P<0.01$
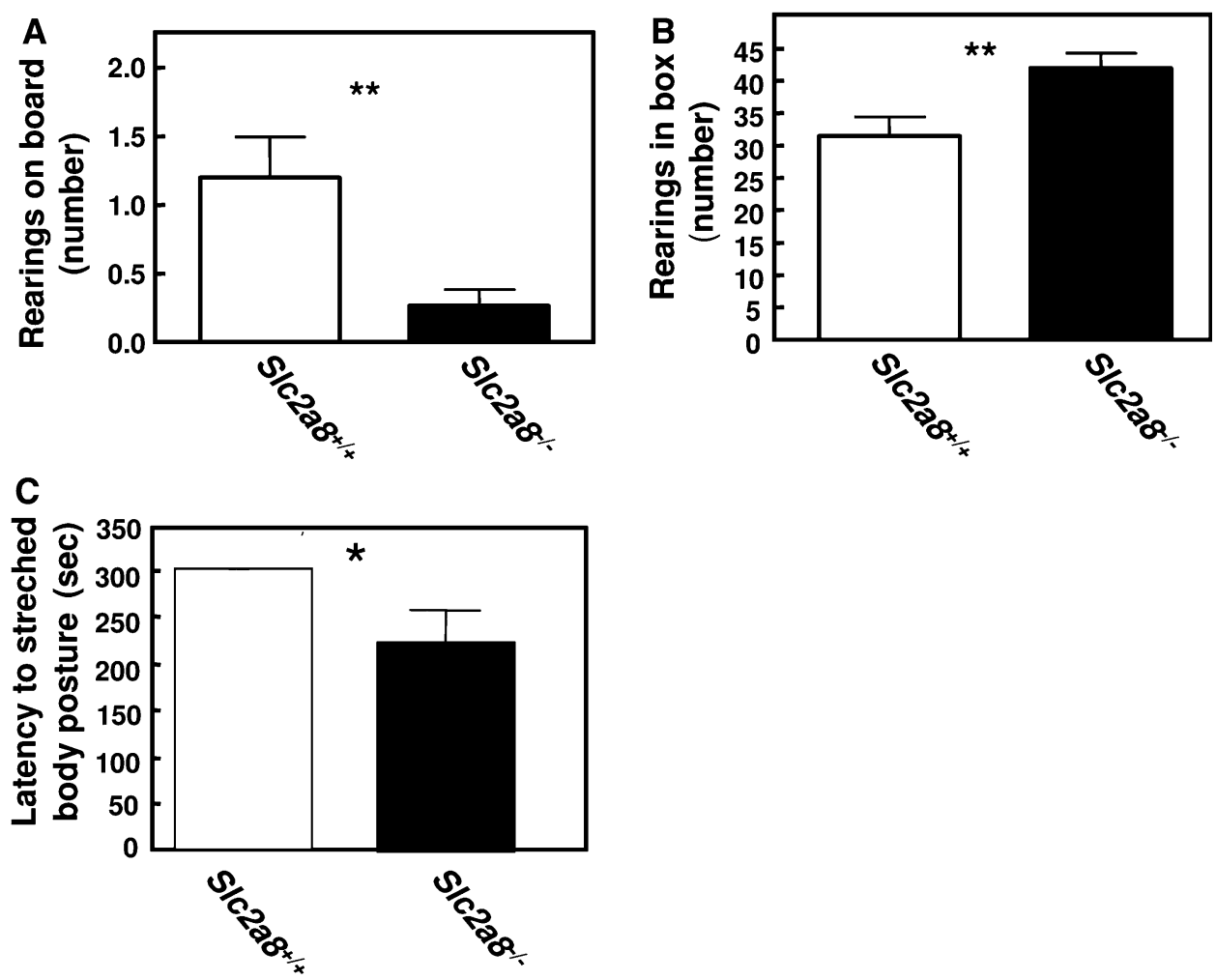

malabsorption causes the increased defecation of Slc $2 a 8^{-1-}$ mice. In addition, the body weight (Gawlik et al. 2008) and other metabolic parameter, such as energy uptake, food consumption, and food assimilation did not differ between control and knockout mice at the age of 18 weeks. The finding that 18 -weeks old wild-type and knockout mice produce the same amount of feces (control: $0.8 \pm<0.1$ vs. knockout: $0.8 \pm<0.1$ g per day) indicates that deletion of GLUT8 does not affect the energy metabolism. Since we only observed increased defecation of naïve mice in an unknown novel environment we conclude that this is a result of an altered emotional reactivity. In addition, the latency to the first grooming another indictor for arousal (Ohl et al. 2003) was slightly reduced supporting the assumption of an increased arousal in the absence of GLUT8.

The altered rearing pattern and stretched body posture indicated that $S l c 2 a 8^{-/-}$mice exhibit a decreased risk assessment. That only four out of 15 Slc $2 a 8^{-1-}$ males displayed risk assessment behavior indicates that it is only a moderate effect. It may also partly be due to the short duration of the measurement (300 s).

Finally, knockout mice showed trends towards decreased entries on board, and reduced time spent on board and, parameters reflecting anxiety-related behavior (Ohl et al. 2003). However, since these effects were not significant it will be necessary to perform additional tests which specifically determine the level of anxiety, such as 
the open field, elevated plus maze or the light-dark avoidance test.

Several of our observations performed in the mHB test show only a tendency towards behavioral alterations. Since our screen was performed with mice which were backcrossed three times onto a C57BL/6 background it is possible that on the one hand the Slc2a8 knockout on a pure background would reduce the inter-individual variability, leading to more significant results. On the other hand, moderate effects shown with the N3 generation could be due to heterogeneous background and not be verified in congenic mice. As reported by Yang et al. (2005) the phenotype of knockout mice is significantly influenced by the genetic background. However, in order to minimize differences due to genetic background we compared wildtype and knockout littermates of 5-7 litters because they should exhibit a comparable background.

The hippocampus has been shown to play a crucial role in behavior in rodents (Goddyn et al. 2006). Hippocampuslesioned rodents were described to be dramatically more active than controls (Bardgett et al. 2003; Deacon et al. 2002; Torremans et al. 2005). Furthermore, the size of the hippocampal lesion correlated with the degree of hyperactivity (Goddyn et al. 2006). The hippocampus is also involved in the regulation of anxiety-related behaviors (Deacon et al. 2002). Both anxiogenic as well as anxiolytic effects of hippocampal lesions have been described in rodents (Goddyn et al. 2006). Respectively, similar results have been reported for electrical stimulation of the amygdala. Dependent on the site of stimulation anxiogenic or anxiolytic effects have been reported (Adamec and Morgan 1994; Witkin et al. 1988). Consistent with the site of stimulation or lesion, the latency to explore the center of the open field was altered reciprocally. Due to the finding that GLUT8 is expressed in several regions of the brain (Fig. 1) we cannot specifically define which area is responsible for the behavioral alterations of $S l c 2 a 8^{-1-}$ mice.

Recently, it has been reported that deletion of GLUT8 in mice led to increased cell proliferation in the dentate gyrus (Membrez et al. 2006). Although the hippocampus was described to play an important role in memory acquisition and some studies have even linked this with increased proliferation of neurons in the dentate gyrus (Kempermann and Gage 2002; van Praag et al. 1999), no differences between $\operatorname{Slc} 2 a 8^{-1-}$ and wild-type mice was observed with the Morris water maze or the homing board task (Membrez et al. 2006). Since Slc $2 a 8^{-1-}$ mice explored unfamiliar and familiar objects in the same frequency as $S l c 2 a 8^{+/+}$males our data support the result of Membrez et al. (2006). This is in line with a previous report of increased hippocampal neurogenesis without spatial learning improvement in mice bred for increased voluntary wheel running (Rhodes et al. 2003).

Due to the fact that the hippocampus is more susceptible to damage by hypoglycaemia and hypoxia than other brain regions (McEwen et al. 1997; Chalmers et al. 1991; Ng et al. 1989) and the high expression of GLUT8 in hippocampus, we consequently suggest that altered glucose metabolism in hippocampal cells in the absence of GLUT8 results in hyperactivity, increased arousal, and reduced risk assessment without affecting memory acquisition. However, we cannot rule out that other brain regions than hippocampus are involved in this phenotype. Since most studies demonstrated that GLUT8 is located in intracellular compartments (Lisinski et al. 2001; Piroli et al. 2002; Augustin et al. 2005) it is not clear how GLUT8 might influence glucose homeostasis.

In summary, our study showed that in mice GLUT8 is mainly expressed in the hippocampus and that mice lacking GLUT8 show hyperactivity, increased arousal and reduced risk assessment. Up to now it is not clear how the behavioral phenotype can be explained by the function of GLUT8. According to the observation of Slc $2 a 8^{-1-}$ spermatozoa which show reduced motility due to reduced mitochondrial membrane potential and ATP levels (Gawlik et al. 2008) we can only speculate that according to sperm cells GLUT8 plays a role in the energy metabolism of hippocampus.

Acknowledgments This work was supported by the Deutsche Forschungsgemeinschaft (VG: GK1208, RA: AU178/3-1; AS: FOR441). This work has been funded by the Federal Ministry of Education and Research (BMBF) in the framework of the National Genome Research Network (NGFN; 01GR0430) and by the European Union (FP6, EUMODIC, LSHG-CT-2006-037188).

Open Access This article is distributed under the terms of the Creative Commons Attribution Noncommercial License which permits any noncommercial use, distribution, and reproduction in any medium, provided the original author(s) and source are credited.

\section{References}

Adamec RE, Morgan HD (1994) The effect of kindling of different nuclei in the left and the right amygdala on anxiety in the rat. Physiol Behav 55:1-12

Augustin R, Riley J, Moley KH (2005) GLUT8 contains a $[\mathrm{DE}] \mathrm{XXXL}[\mathrm{LI}]$ sorting motif and localizes to a late endosomal/lysosomal compartment. Traffic 6:1196-1212

Bannerman DM, Lemaire M, Beggs S, Rawlins JNP, Iversen SD (2001) Cytotoxic lesions of the hippocampus increase social investigation but do not impair social recognition memory. Exp Brain Res 138:100-109

Bannerman DM, Grubb M, Deacon RMJ, Yee BK, Feldon J, Rawlins JNP (2003) Ventral hippocampal lesions affect anxiety but not spatial learning. Behav Brain Res 139:197-213 
Bardgett ME, Boeckman R, Krochmal D, Fernando H, Ahrens R, Csernansky JG (2003) NMDA receptor blockade and hippocampal neuronal loss impair fear conditioning and position habit reversal in C57B1/6 mice. Brain Res Bull 60:131-142

Bliss TV, Collingridge GL (1993) A synaptic model of memory: long-term potentiation in the hippocampus. Nature 361:31-39

Buchmann J, Meyer C, Neschen S, Augustin R, Schmolz K, Kluge R, Al-Hasani H, Jurgens H, Eulenberg K, Wehr R, Dohrmann C, Joost HG, Schürmann A (2007) Ablation of the cholesterol transporter adenosine triphosphate-binding cassette transporter G1 reduces adipose cell size and protects against diet-Induced obesity. Endocrinology 148:1561-1573

Chalmers J, Risk MTA, Kean DM, Grant R, Ashworth B, Campbell IW (1991) Severe amnesia after hypoglycemia. Clinical, psychometric, and magnetic resonance imaging correlations. Diabetes Care 14:922-925

Convit A, de Asis J, de Leon MJ, Tarshish CY, De Santi S, Rusinek H (2000) Atrophy of the medial occipitotemporal, inferior, and middle temporal gyri in non-demented elderly predict decline to Alzheimer's disease. Neurobiol Aging 21:19-26

Convit A, Wolf OT, Tarshish C, de Leon MJ (2003) Reduced glucose tolerance is associated with poor memory performance and hippocampal atrophy among normal elderly. Proc Natl Acad Sci USA 100:2019-222

Deacon RMJ, Bannerman DM, Rawlins JNP (2002) Anxiolytic effects of cytotoxic hippocampal lesions in rats. Behav Neurosci 116:494-497

File SE, Wardill AG (1975) Validity of head-dipping as a measure of exploration in a modified hole-board. Psychopharmacologia (Berl) 44:53-59

Gawlik V, Schmidt S, Scheepers A, Wennemuth G, Augustin R, Aumüller G, Moser M, Al-Hasani H, Kluge R, Joost HG, Schürmann A (2008) Targeted disruption of Slc2a8 (GLUT8) reduces motility and mitochondrial potential of spermatozoa. Mol Membr Biol 25:224-235

Goddyn H, Leo S, Meert T, D'Hooge R (2006) Differences in behavioral test battery performance between mice with hippocampal and cerebellar lesions. Behav Brain Res 173:138-147

Harr SD, Simonian NA, Hyman BT (1995) Functional alterations in Alzheimer's disease: decreased glucose transporter 3 immunoreactivity in the perforant pathway terminal zone. J Neuropathol Exp Neurol 54:38-41

Honey RC, Marshall VJ, McGregor A, Futter J, Good M (2007) Revisiting places passed: sensitization of exploratory activity in rats with hippocampal lesions. Q J Psychol (Colchester) 60: 625-634

Ibberson M, Uldry M, Thorens B (2000) GLUTX1, a novel mammalian glucose transporter expressed in the central nervous system and insulin-sensitive tissues. $J$ Biol Chem 275: 4607-4612

Ibberson M, Riederer BM, Uldry M, Guhl B, Roth J, Thorens B (2002) Immunolocalization of GLUTX1 in the testis and to specific brain areas and vasopressin-containing neurons. Endocrinology 143:276-284

Jack CR, Petersen RC, Xu YC, O'Brien PC, Smith GE, Ivnik RJ, Boeve BF, Waring SC, Tangalos EG, Kokmen E (1999) Prediction of AD with MRI-based hippocampal volume in mild cognitive impairment. Neurology 52:1397-1403

Johnson KA, Jones K, Holman BL, Becker JA, Spiers PA, Satlin A, Albert MS (1998) Preclinical prediction of Alzheimer's disease using SPECT. Neurology 50:1563-1571

Joost HG, Thorens B (2001) The extended GLUT-family of sugar/ polyol transport facilitators: nomenclature, sequence characteristics, and potential function of its novel members. Mol Membr Biol 18:247-256
Jurgens HS, Schürmann A, Kluge R, Ortmann S, Klaus S, Joost HG, Tschop MH (2006) Hyperphagia, lower body temperature, and reduced running wheel activity precede development of morbid obesity in New Zealand obese mice. Physiol Genomics 25:234241

Kallnik M, Elvert R, Ehrhardt N, Kissling D, Mahabir E, Welzl G, Faus-Kessler T, Hrabe de Angelis M, Wurst W, Schmidt J, Hölter SM (2007) Impact of IVC housing on emotionality and fear learning in male $\mathrm{C} 3 \mathrm{HeB} / \mathrm{FeJ}$ and C57BL/6J mice. Mamm Genome 18:173-186

Kelley AE (1993) Locomotor activity and exploration. In: Sahgal A (ed) Behavioral neuroscience: a practical approach. Oxford University Press, Oxford, pp 1-21

Kempermann G, Gage FH (2002) Genetic determinants of adult hippocampal neurogenesis correlate with acquisition, but not probe trial performance, in the water maze task. Eur J Neurosci $16: 129-136$

Killiany RJ, Gomez-Isla T, Moss M, Kikinis R, Sandor T, Jolesz F, Tanzi R, Jones K, Hyman BT, Albert MS (2000) Use of structural magnetic resonance imaging to predict who will get alzheimer's disease. Ann Neurol 47:430-439

Lisinski I, Schürmann A, Joost HG, Cushman SW, Al-Hasani H (2001) Targeting of GLUT6 (formerly GLUT9) and GLUT8 in rat adipose cells. Biochem J 358:517-522

Lister RG (1990) Ethologically based animal models of anxiety disorders. Pharmacological Therapy 46:321-340

Livak KJ, Schmittgen TD (2001) Analysis of relative gene expression data using realtime quantitative PCR and the $2\left(-\Delta \Delta \mathrm{C}_{\mathrm{T}}\right)$ method. Methods 25:402-440

McEwen BS (1997) Possible mechanisms for atrophy of the human hippocampus. Mol Psychiatry 2:255-262

Membrez M, Hummler E, Beermann F, Haefliger JA, Savioz R, Pedrazzini T, Thorens B (2006) GLUT8 is dispensable for embryonic development but influences hippocampal neurogenesis and heart function. Mol Cell Biol 26:4268-4276

Nakazawa K, Quirk MC, Chitwood RA, Watanabe M, Yeckel MF, Sun LD (2002) Requirement for hippocampal CA3 NMDA receptors in associative memory recall. Science 297:211-218

$\mathrm{Ng} \mathrm{T}$, Graham DI, Adams JH, Ford I (1989) Changes in the hippocampus and the cerebellum resulting from hypoxic insults: frequency and distribution. Acta Neuropathol 78:438-443

Ohl F, Oitzl MS, Fuchs E (1998) Assessing cognitive functions in tree shrews: visuo-spatial and spatial learning in the home cage. $\mathrm{J}$ Neurosci Methods 81:35-40

Ohl F, Fuchs E (1999) Differential effects of chronic stress on memory processes in the tree shrew. Cogn Brain Res 7:379-387

Ohl F, Holsboer F, Landgraf R (2001) The modified hole board as a differential screen for behavior in rodents. Behav Res Methods Instrum Comput 33:392-397

Ohl F, Roedel A, Binder E, Holsboer F (2003) Impact of high and low anxiety on cognitive performance in a modified hole board test in C57BL/6 and DBA/2 mice. Eur J Neurosci 17:128-136

Ouchi Y, Nobezawa S, Okada H, Yoshikawa E, Futatsubashi M, Kaneko M (1998) Altered glucose metabolism in the hippocampal head in memory impairment. Neurology 51:136-142

Piroli GG, Grillo CA, Hoskin EK, Znamensky V, Katz EB, Milner TA, McEwen BS, Charron MJ, Reagan LP (2002) Peripheral glucose administration stimulates the translocation of GLUT8 glucose transporter to the endoplasmic reticulum in the rat hippocampus. J Comp Neurol 452:103-114

Reagan LP, Gorovits N, Hoskin EK, Alves SE, Katz EB, Grillo CA, Piroli GG, McEwen BS, Charron MJ (2001) Localization and regulation of GLUTx 1 glucose transporter in the hippocampus of streptozotocin diabetic rats. Proc Natl Acad Sci USA 98: 2820-2825 
Rhodes JS, van Praag H, Jeffrey S, Girard I, Mitchell GS, Garland T Jr, Gage FH (2003) Exercise increases hippocampal neurogenesis to high levels but does not improve spatial learning in mice bred for increased voluntary wheel running. Behav Neurosci 117:1006-1016

Sankar R, Thamotharan S, Shin D, Moley KH, Devaskar SU (2002) Insulin-responsive glucose transporters-GLUT8 and GLUT4 are expressed in the developing mammalian brain. Brain Res Mol Brain Res 107:157-165

Scheepers A, Doege H, Joost HG, Schürmann A (2001) Mouse GLUT8: genomic organization and regulation of expression in 3T3-L1 adipocytes by glucose. Biochem Biophys Res Commun 288:969-974

Simpson IA, Chundu KR, Davies-Hill T, Honer WG, Davies P (1994) Decreased concentrations of GLUT1 and GLUT3 glucose transporters in the brains of patients with Alzheimer's disease. Ann Neurol 35:546-551

Torremans A, Marescau B, Van Dam D, Van Ginneken C, Van Meir F, Van Bogaert PP et al (2005) GSA: behavioral, histological, electrophysiological, and neurochemical effects. Physiol Behav $84: 251-264$

van Praag H, Christie BR, Sejnowski TJ, Gage FH (1999) Running enhances neurogenesis, learning, and long-term potentiation in mice. Proc Natl Acad Sci USA 96:13427-13431

Widmer M, Uldry M, Thorens B (2005) GLUT8 subcellular localization and absence of translocation to the plasma membrane in PC12 cells and hippocampal neurons. Endocrinology 146:4727-4736

Witkin JM, Lee MA, Wallczak DD (1988) Anxiolytic properties of amygdaloid kindling unrelated to benzodiazepine receptors. Psychopharmacology 96:296-301

Yang T, Huang YG, Ye W, Hansen P, Schnermann JB, Briggs JP (2005) Influence of genetic background and gender on hypertension and renal failure in COX-2-deficient mice. Am J Physiol Renal Physiol 288:1125-32 